\title{
Feocromocitoma y paraganglioma. Pilares para el manejo de una enfermedad rara
}

\author{
Pheochromocytoma and paraganglioma. Pillars for handling a rare disease
}

El feocromocitoma y el paraganglioma son tumores neuroendocrinos infrecuentes. La localización adrenal o extra-adrenal determina la denominación, feocromocitoma para aquellos adrenales y paraganglioma para los localizados en los paraganglios. En todas las enfermedades raras, pocos centros y personas logran experiencias suficientes para poder llamarse expertos. En este sentido, el personal médico que se enfrenta a los pacientes con feocromocitoma o paraganglioma se ve retado a actualizarse en una enfermedad infrecuente, para la que apenas recientemente se crearon guías y para la que la mayoría de médicos no alcanzará a manejar un paciente con esta entidad en su vida académica. De allí que el diagnóstico sea difícil y el manejo y seguimiento heterogéneo.

En este número de Medicina \& Laboratorio se presenta una revisión de tema sobre feocromocitoma y paraganglioma como un paso inicial de educación médica continua y, en particular, para alertar a la población médica sobre dos tópicos a veces olvidados en el manejo del paciente con este tipo de tumor neuroendocrino, la posibilidad de malignidad y el seguimiento de por vida que necesitan estos pacientes. Respecto al primer punto, previamente se consideraba al feocromocitoma y al paraganglioma la enfermedad del 10\%, dado que se estimaba que el 10\% eran de origen genético, 10\% eran bilaterales, $10 \%$ malignos, $10 \%$ extra-adrenales y $10 \%$ en niños. Sin embargo, los feocromocitomas hoy en día tienen un evento genético somático o germinal hasta en el 50\% de los casos y más del $10 \%$ son malignos.

EL feocromocitoma o paraganglioma maligno es definido por la Organización Mundial de Salud (OMS) como aquel que presenta metástasis, sin existir a la fecha un marcador clínico o paraclínico que pueda definir la malignidad; sin embargo, la presencia de un tumor mayor de $5 \mathrm{~cm}$, una localización extra-adrenal o mutaciones en el gen SDHB son predictores clínicos de malignidad y, en estos casos, los pacientes pueden requerir estudios funcionales, por ejemplo una gammagrafía con metayodobencilguanidina (MIBG), y un seguimiento estrecho prolongado. Además, las metástasis se pueden presentar incluso varias décadas después de la resección del tumor primario, por ende, estos pacientes requieren controles anuales de por vida con metanefrinas urinarias o plasmáticas y cada dos a tres años una imagen de control.

Por otro lado, para el feocromocitoma o paraganglioma maligno existen hoy en día alternativas terapéuticas y no debe ser considerado una enfermedad sin tratamiento. Desde el punto de vista oncológico se pueden observar activamente estos pacientes para definir progresión y, una vez se documente la misma, se puede utilizar quimioterapia o terapia con radioisótopos (II3I-MIBG). A futuro, los estudios con inhibidores de las tirosina quinasas como el sunitinib, el pazopanib o el cabozantinib van a aclarar el papel de estos medicamentos en esta enfermedad. 
Otro progreso importante para el feocromocitoma y paraganglioma son los desarrollos genéticos. Previamente eran pocos los pacientes que se consideraban para estudios genéticos; principalmente se realizaban en aquellos que tenían mayor probabilidad como son los pacientes que presentan estos tumores a temprana edad, bilaterales o malignos. Sin embargo, hoy en día todos los pacientes deben tener consejería genética y definir luego de la misma si desean estudio genético para confirmar algunas de las alteraciones descritas. El único caso donde no es necesaria una confirmación genética es en los pacientes con neurofibromatosis dado que el diagnóstico es con base en criterios clínicos. El diagnóstico genético se ha facilitado por la disponibilidad de paneles genéticos que evalúan por secuenciación de nueva generación la presencia de mutaciones en los 14 genes descritos hasta la fecha asociados al feocromocitoma. El reto en nuestra práctica clínica diaria es poder acceder a estas pruebas.

Finalmente, se recuerda al lector que la disponibilidad de las pruebas de detección de metanefrinas en orina o plasmáticas, con mejor sensibilidad y especificidad para el diagnóstico de feocromocitoma, hace obsoleto la medición de las catecolaminas en plasma o del ácido vanilmandélico. Esperemos entonces que la revisión publicada en este número de Medicina \& Laboratorio logre el objetivo de mejorar el diagnóstico, manejo y tratamiento de los pacientes con feocromocitoma y paraganglioma, y hacemos un llamado a la población médica a retomar aquellos pacientes que no han tenido seguimiento y ofrecer una oportunidad de tratamiento a aquellos con feocromocitoma o paraganglioma maligno.

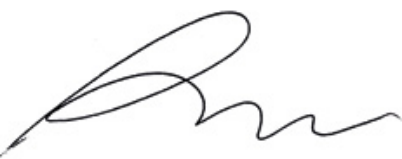

\section{Alejandro Román González MD, Internista, Endocrinólogo}

Departamento de Endocrinología, Hospital Universitario San Vicente Fundación

Grupo Antioqueño de Tumores Neuroendocrinos-GAE

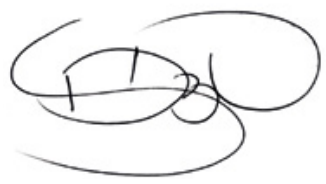

\section{Luz Deisser Suárez Vásquez MD, Internista, Oncóloga}

Departamento de Oncología, Instituto de Cancerología Clínica Las Américas

Grupo Antioqueño de Tumores Neuroendocrinos-GAE

\section{Medellín, Colombia, abril 2015}

